\title{
Environmental Stress and Methyl Jasmonate-mediated Changes in Flavonoid Concentrations and Antioxidant Activity in Broccoli Florets
and Kale Leaf Tissues
}

\author{
Kang Mo Ku and John A. Juvik ${ }^{1}$ \\ Department of Crop Sciences, University of Illinois at Urbana-Champaign, \\ 307 Edgar R. Madigan Lab, 1201 West Gregory Drive, Urbana, IL 61801-3838
}

Additional index words. Brassica oleracea, ABTS, DPPH, quercetin, kaempferol, environmental stress

\begin{abstract}
Aqueous solutions of $250 \mu \mathrm{M}$ methyl jasmonate (MeJA) were sprayed on aerial plant surfaces 4 days before harvest at commercial maturity of five commercial broccoli (Brassica oleracea L. var. italica) hybrids, 'Pirate', 'Expo', 'Imperial', 'Gypsy', and 'Green Magic', and two kale cultivars, Red Winter (Brassica napus ssp. pabularia) and Dwarf Blue Curled Vates (Brassica oleracea L. var. acephala DC.) in replicated field trials over 2 years. While having no effect on broccoli floret concentrations, MeJA treatments significantly increased total phenolics in kale cultivars over two seasons by $27 \%$ and extract antioxidant activity by $31 \%$ using the 2,2-diphenyl-1-picrylhydrazyl (DPPH) assay. Partitioning experiment-wide trait variances indicated that the variability in broccoli floret concentrations of total phenolics (74\%), quercetin (24\%), kaempferol (34\%), and 2,2'-azino-bis(3-ethylbenzothiazoline-6-sulphonic acid) diammonium salt (ABTS) (66\%) and DPPH (62\%) antioxidant activity was largely influenced by yearassociated environmental factors. In broccoli, the differential accumulation of solar radiation among cultivars resulting from the variation in days to maturity was significantly correlated with total phenolics, ABTS, and DPPH antioxidant activity. Broccoli floret and kale total phenolic, quercetin, and kaempferol concentrations significantly correlated with DPPH and ABTS antioxidant activity. To summarize, total phenolic and flavonoid concentrations and their associated antioxidant activity in broccoli florets were unaffected by MeJA but varied significantly among cultivars and over growing seasons. Apical, compared with basal, leaves in kale were more responsive to MeJA-mediated increases in total phenolics and ABTS and DPPH antioxidant activity.
\end{abstract}

Numerous physiological and biochemical processes in the human body may produce oxygen-centered free radicals and other reactive oxygen species as byproducts of metabolism (Cai et al., 2004). Overproduction of free radicals can cause oxidative damage to biomolecules including lipids, proteins, and DNA, eventually leading to many chronic diseases such as atherosclerosis, cancer, and other degenerative diseases in humans (Cai et al., 2004; Valko et al., 2004). Dietary antioxidants including polyphenols and flavonoids protect against free radicals such as reactive oxygen species in the human body and have been associated with the prevention of cancer, Type 2 diabetes, and cardiovascular diseases (Moon et al., 2006; Poulsen et al., 1998, van Dam et al., 2013). Fruit and vegetables are good sources of natural antioxidants such as vitamins, carotenoids, flavonoids, and other phenolic compounds (Dimitrios, 2006).

Received for publication 22 May 2013. Accepted for publication 20 June 2013.

${ }^{1}$ To whom reprint requests should be addressed; e-mail juvik@illinois.edu. flavonoids, both vegetables have a variety of additional polyphenol compounds such as hydroxycinnamic acid and hydroxybenzoic acid derivatives. Among them, ferulic acid and chlorogenic acid were reported to improve cardiovascular function and attenuate hypertension in hypertensive rats (Alam et al., 2013; Suzuki et al., 2006).

Biotic and abiotic factors are associated with the biosynthesis and accumulation of phenolics and flavonoids in plant tissues. Environmental factors such as temperature, solar radiation, and rainfall can influence broccoli metabolism and resulting phytochemical composition (Björkman et al., 2011; Gliszczynska-Swiglo et al., 2007; Khan et al., 2011). Also, herbivore or pathogen activity also can influence broccoli phytochemical composition (Hopkins et al., 2009; Khan et al., 2011). Recently many studies have been conducted using exogenous treatments of elicitors including jasmonic acid and salicylic acid to mimic biotic stress and increase tissue total phenolics and flavonoid concentrations. Several reports have attempted to enhance antioxidant, antiproliferative, and antiadipogenic activity by MeJA-mediated increases in flavonoids or phenolics in sweet basil, buckwheat, and blackberry, respectively (Kim et al., 2006b; Lee et al., 2013; Wang et al., 2008).

The objective of this research was to investigate how MeJA applications and year-to-year variation in environment growing conditions affect total phenolics, flavonoid concentrations, and antioxidant activity of broccoli floret and kale leaf tissues. To our knowledge, this is the first investigation of MeJA application to broccoli and kale under field conditions. To evaluate variation in phytochemical antioxidants and antioxidant activity associated with MeJA treatments, environment effects, and genotypes, we evaluated five commercial broccoli hybrids and two distinct kale cultivars in replicated field plots over 2 years.

\section{Materials and Methods}

quently consumed vegetables i States and in other countries. They contain potential health-promoting bioactive compounds including glucosinolates and dietary antioxidants such as carotenoids, tocopherols, and flavonoids (Eberhardt et al., 2005, Velasco et al., 2007). Both vegetables are good sources of the dietary flavonoids, quercetin and kaempferol, which have been reported as potential anticancer agents (Koh et al., 2009; Moon et al., 2006). According to epidemiological and animal model studies, consumption of kaempferol and quercetin was inversely associated with cancer risk (Gates et al., 2007; Murakami et al., 2008; Neuhouser, 2004; Nothlings et al., 2007). Quercetin intake has also been associated with decreasing blood pressure (Larson et al., 2012). A recent study has indicated that quercetin up-regulates lowdensity lipoprotein receptor gene expression, which can elicit hypolipidemic effects by improving the clearance of circulating lowdensity lipoprotein cholesterol levels from the blood (Moon et al., 2012). In addition to the
Broccoli and kale cultivation. The broccoli $F_{1}$ hybrid cultivars used for this experiment were 'Pirate' (Asgrow Seed Co., Galena, MD), 'Expo', 'Imperial', 'Gypsy', and 'Green Magic' (Sakata Seed Co., Morgan Hill, CA). Kale cultivars used for this experiment were 'Red Winter' (Brassica napus ssp. pabularia) and 'Dwarf Blue Curled Vates' (Brassica oleracea L. var. acephala DC.). Seeds of each broccoli and kale genotype were germinated in 32-cell plant plug trays filled with Sunshine ${ }^{\circledR}$ LC1 (Sun Gro Horticulture, Vancouver, British Columbia, Canada) professional soil mix. Seedlings were grown in a greenhouse at the University of Illinois at ChampaignUrbana under a $25 / 15{ }^{\circ} \mathrm{C}$ and $14-\mathrm{h} / 10$-h day/night temperature regime with supplemental high-intensity discharge lighting provided from 0600 to $2000 \mathrm{HR}$ if light intensities fell below $2670 \mu$ Einsteins $/ \mathrm{s} / \mathrm{m}^{2}$. Thirty days after germination, seedling trays were placed in ground beds to harden off for 1 week before 
transplanting into field plots at the University of Illinois South Farm (lat. $40^{\circ} 04^{\prime} 38.89^{\prime \prime}$ N, long. $88^{\circ} 14^{\prime} 26.18^{\prime \prime} \mathrm{W}$ ). The experimental design was a split plot in randomized complete block with three replicates. The experiment plot was surrounded by one row of guard plants to avoid a border effect. Ten broccoli or kale plants from each replicate block of each genotype were designated as control or MeJA treatment groups with each genotype. Transplanting of broccoli seedlings was conducted on 24 June 2009 and 11 June 2010. Irrigation was only applied during the first week of cultivation to establish transplanted seedlings. Broccoli heads were harvested between 23 Aug. and 18 Sept. in 2009 and from 12 Aug. to 12 Sept. in 2010. Transplanting of kale seedlings was conducted on 11 June 2010 and 13 June 2011. Harvests of leaves of both kale cultivars occurred on 25 July in 2009 and 27 July in 2010 . There was substantial variation in commercial harvest maturity among broccoli hybrids and the number of days from transplant to harvest date (DTH) was calculated for each genotype (Table 1). Variation in weather factors during the growing seasons in Champaign, IL, for 2009, 2010, and 2011 including growing degree-days (GDDs) [formula $=($ minimum temperature + maximum temperature) $/ 2-7.2^{\circ} \mathrm{C}$ ] (Dufault, 1997), solar radiation, and precipitation, is presented in Supplementary Table 1 . Weather conditions during the 2009 and 2010 growing seasons were generated from $<\mathrm{http}$ ://www.isws.illinois. edu/warm/data/cdfs/cmiday.txt $>$ and used to calculate these weather variables.

Treatment with MeJA and sample preparation. An aqueous solution of $250 \mu \mathrm{M}$ MeJA (Sigma-Aldrich, St. Louis, MO) including $0.1 \%$ Triton X-100 (Sigma-Aldrich) or $0.1 \%$ Triton X-100 alone (control) was sprayed on all aerial plant tissues to the point of runoff $(\approx 200 \mathrm{~mL}) 4 \mathrm{~d}$ before harvest at

commercial maturity. This timing of harvest and treatment concentration was based on previous studies that identified optimal timing and MeJA concentrations to maximize floret glucosinolate concentrations in broccoli cultivars (Ku and Juvik, 2012). Five broccoli heads and two leaf samples from each kale cultivar (apical: three leaves from below the meristematic growing point, at a minimum $8 \mathrm{~cm}$ in length; basal: three fully expanded leaves nearest the soil surface without discoloration or signs of senescence or damage) were harvested and bulked from five treated and control plants of each genotype for each replicate (five heads or leaves from five plants bulked for a replicate sample). Broccoli head tissue and kale leaf samples were frozen in liquid nitrogen and stored at $-20{ }^{\circ} \mathrm{C}$ before freeze-drying. Freeze-dried head and leaf tissues were ground into a fine powder using a coffee grinder and stored at $-20{ }^{\circ} \mathrm{C}$ before chemical and bioactivity analyses.

Sample extraction. Two hundred milligrams of fine powder of each sample was extracted with $2 \mathrm{~mL}$ of $70 \%$ methanol at $95^{\circ} \mathrm{C}$ for $10 \mathrm{~min}$. After $5 \mathrm{~min}$ cooling on ice, the extract was centrifuged at $3000 \mathrm{~g}$ for $10 \mathrm{~min}$. After a second round of extraction as described previously, the supernatants were pooled. Subsequently, $1.5 \mathrm{~mL}$ of the pooled supernatant was transferred to a $2-\mathrm{mL}$ microcentrifuge tube (Fisher Scientific, Waltham, MA) and centrifuged at $10,000 \mathrm{~g}$ for $2 \mathrm{~min}$. This extract was used for the ABTS and DPPH antioxidant activity assays and to quantify tissue total phenolic and flavonoid concentrations.

Determination of sample flavonoid concentrations. The sample extracts from broccoli and kale were transferred $(1.2 \mathrm{~mL})$ to a 2-mL microcentrifuge tube (Fisher Scientific) to which $0.24 \mathrm{~mL}$ of $6 \mathrm{M} \mathrm{HCl}$ was

Table 1. Days to harvest (DTH), growing degree-days (GDDs), solar radiation, and precipitation accumulation for the five broccoli genotypes during the 2009 and 2010 growing seasons. $^{\mathrm{z}}$

\begin{tabular}{|c|c|c|c|c|c|c|}
\hline Year & Cultivar & Treatment & DTH & $\operatorname{GDD}\left({ }^{\circ} \mathrm{C}\right)^{\mathrm{y}}$ & $\begin{array}{c}\text { Solar radiation } \\
\left(\mathrm{MJ} \cdot \mathrm{m}^{-2)}\right.\end{array}$ & $\begin{array}{l}\text { Precipitation } \\
(\mathrm{mm})\end{array}$ \\
\hline \multirow[t]{2}{*}{$\overline{2009}$} & Expo & Control & $81 \pm 3$ & 1150 & 1705 & 296 \\
\hline & Expo & MeJA & $82 \pm 3$ & 1163 & 1729 & 296 \\
\hline \multirow[t]{2}{*}{2009} & Green Magic & Control & $58 \pm 7$ & 859 & 1257 & 223 \\
\hline & Green Magic & MeJA & $57 \pm 7$ & 846 & 1239 & 222 \\
\hline \multirow[t]{2}{*}{2009} & Gypsy & Control & $62 \pm 5$ & 906 & 1342 & 223 \\
\hline & Gypsy & MeJA & $61 \pm 2$ & 893 & 1318 & 223 \\
\hline \multirow[t]{2}{*}{2009} & Imperial & Control & $60 \pm 3$ & 881 & 1293 & 223 \\
\hline & Imperial & MeJA & $60 \pm 2$ & 881 & 1293 & 223 \\
\hline \multirow[t]{2}{*}{2009} & Pirate & Control & $77 \pm 5$ & 1094 & 1622 & 296 \\
\hline & Pirate & MeJA & $78 \pm 5$ & 1109 & 1643 & 296 \\
\hline \multirow[t]{2}{*}{2010} & Expo & Control & $88 \pm 2$ & 1531 & 2758 & 314 \\
\hline & Expo & MeJA & $93 \pm 3$ & 1595 & 2868 & 318 \\
\hline \multirow[t]{2}{*}{2010} & Green Magic & Control & $67 \pm 6$ & 1198 & 2165 & 245 \\
\hline & Green Magic & MeJA & $67 \pm 6$ & 1198 & 2165 & 245 \\
\hline \multirow[t]{2}{*}{2010} & Gypsy & Control & $68 \pm 3$ & 1215 & 2193 & 245 \\
\hline & Gypsy & MeJA & $69 \pm 2$ & 1231 & 2223 & 245 \\
\hline \multirow[t]{2}{*}{2010} & Imperial & Control & $65 \pm 2$ & 1107 & 2100 & 245 \\
\hline & Imperial & MeJA & $66 \pm 4$ & 1182 & 2136 & 245 \\
\hline \multirow[t]{2}{*}{2010} & Pirate & Control & $92 \pm 6$ & 1581 & 2825 & 314 \\
\hline & Pirate & MeJA & $91 \pm 4$ & 1570 & 2845 & 314 \\
\hline
\end{tabular}

${ }^{\mathrm{z}}$ The accumulated weather variables were calculated based on number of days from transplant to harvest. ${ }^{\mathrm{y}}\left[(\right.$ Minimum temperature + maximum temperature $\left.) / 2-7.2^{\circ} \mathrm{C}\right]$. The results are presented as means $\pm \mathrm{SD}$ $(\mathrm{n}=3)$.

$\mathrm{MeJa}=$ methyl jasmonate. added. The tubes were then heated at $90{ }^{\circ} \mathrm{C}$ for $2 \mathrm{~h}$ to release the aglycone (Kurilich et al., 2002). The extract was cooled and filtered through a $0.45-\mu \mathrm{m}$ PTFE Whatman (Clifton, NJ) membrane filter before injection onto the high-performance liquid chromatograph (HPLC). Flavonoid concentrations were evaluated using an Agilent 1100 HPLC system (Agilent, Santa Clara, CA) equipped with a G1311A bin pump, a G1322A vacuum degasser, a G1316A thermostatic column compartment, a G1315B diode array detector, and an HP 1100 series G1313A autosampler. Extracts were separated on a Supercosil ${ }^{\mathrm{TM}}$ LC-18 column $(250 \times 4 \mathrm{~mm}$, particle size $5 \mu \mathrm{m}$ ) (Supelco Inc., Bellefonte, PA) with a C18 all-guard ${ }^{\mathrm{TM}}$ cartridge pre-column (Alltech, Lexington, KY). Mobile phase A was water and $\mathrm{B}$ was methanol with $0.1 \%$ acetic acid. Mobile phase $\mathrm{B}$ was $0 \%$ at injection, increasing to $60 \%$ by $15 \mathrm{~min}, 80 \%$ at $20 \mathrm{~min}$, and $100 \%$ at $25 \mathrm{~min}$, then held for $5 \mathrm{~min}$ with a $2 \mathrm{~mL} \cdot \mathrm{min}^{-1}$ flow rate, then decreased to $0 \%$ by $35 \mathrm{~min}$. Flow rate was kept at $1 \mathrm{~mL} \cdot \mathrm{min}^{-1}$ except for the $5 \mathrm{~min}$ when mobile phase B was held at $100 \%$. The detector wavelength was set at $360 \mathrm{~nm}$. Quercetin and kaempferol (Sigma-Aldrich) were used as standards for determination of aglycone flavonoid concentration.

Determination of total phenolic content. Analysis of total phenolic content was conducted using a previously described protocol ( $\mathrm{Ku}$ et al., 2010). Ten-microliter sample extracts were added to $0.2 \mathrm{~N}$ Folin-Ciocalteu's phenol reagent $(100 \mu \mathrm{L})$ in 96 -well plates. After $3 \mathrm{~min}, 90 \mu \mathrm{L}$ of a saturated sodium carbonate solution was added to the mixture and subsequently incubated at room temperature for $1 \mathrm{~h}$. The resulting absorbance of the mixture was measured at $630 \mathrm{~nm}$ using a BioTek EL 808 microplate reader (Power Wave XS; Biotek Instruments Inc., Winooski, VT). The total phenolic content was calculated on the basis of a standard curve using gallic acid (concentration range 31.25 to 500 $\left.\mu \mathrm{g} \cdot \mathrm{mL}^{-1}\right)$. Results are expressed in milligrams of gallic acid equivalents per $100 \mathrm{~g}$ of dried broccoli. Three biologically replicated (block) samples were assayed with three analytical replications each.

Determination of ABTS radical scavenging activity. The ABTS assay was conducted as previously described protocol $(\mathrm{Ku}$ et al., 2010). Briefly, $7 \mathrm{~mm}$ ABTS ammonium salt was dissolved in a potassium phosphate buffer ( $\mathrm{pH} 7.4$ ) and treated with $2.45 \mathrm{~mm}$ potassium persulfate. The mixture was then allowed to stand at room temperature for 12 to $16 \mathrm{~h}$ for full color development (dark blue). The solution was then diluted with potassium phosphate buffer until absorbance reached $1.0 \pm 0.02$ at $630 \mathrm{~nm}$ using a BioTek EL 808 microplate reader (Power Wave XS; Biotek Instruments Inc.). Subsequently, $190 \mu \mathrm{L}$ of this solution was mixed with $10 \mu \mathrm{L}$ of sample extracts. The absorbance was recorded at room temperature after $6 \mathrm{~min}$. Results were expressed as a percentage of radical scavenging activity compared with controls. Three biologically 
replicated (block) samples were assayed in three analytical replications.

Determination of the antioxidant activity by the DPPH free radical scavenging assay. The DPPH assay was conducted as described by $\mathrm{Ku}$ et al. (2010) with minor modification. Reaction mixtures containing test samples $(10 \mu \mathrm{L})$ and $190 \mu \mathrm{L}$ of a $200 \mu \mathrm{M}$ DPPH ethanol solution were incubated at room temperature for $30 \mathrm{~min}$ in 96-well plates. The absorbance of the DPPH free radical was measured at $515 \mathrm{~nm}$ with a BioTek EL 808 microplate reader (Power Wave XS; Biotek Instruments Inc.). Results were expressed as percentage of scavenging activity compared with control. Three biologically replicated (block) samples were assayed in three analytical replications. It is generally recommended to use at least two different types of assays for the investigation of antioxidant activities of samples because each assay has different characteristics (Moon and Shibamoto, 2009). For example, the DPPH method is one of the most frequently used antioxidant assay but it is also sensitive to $\mathrm{pH}$ (Huang et al., 2005). To generate robust results, we used the two different scavenging radical assays.

Statistical analysis. JMP 10 software (SAS Institute Inc., Cary, NC) was used for statistical analysis. Analysis of variance and partitioning of variance components were conducted also using JMP 10. Treatments, genotype, and year effects were considered as fixed factors. Block was considered a random factor. Analysis of variance was performed using the linear model: $\mathrm{Y}_{\mathrm{ijklm}}=\mathrm{m}+\mathrm{G}_{\mathrm{i}}+\mathrm{Y}_{\mathrm{j}}+$ $\mathrm{T}_{\mathrm{k}}+\mathrm{GY}_{\mathrm{ij}}+\mathrm{GT}_{\mathrm{ik}}+\mathrm{YT}_{\mathrm{jk}}+\mathrm{GYT}_{\mathrm{ijk}}+\mathrm{B}_{\mathrm{l}(\mathrm{j})}+$ $\varepsilon_{i j k l m}$, where $Y_{i j k l m}$ is the $1^{\text {th }}$ block of the phenotypic value of the $\mathrm{k}^{\text {th }}$ treatment; $\mathrm{i}^{\text {th }}$ genotype in year $\mathrm{j} ; \mathrm{m}$ is the overall mean; $\mathrm{G}$, $\mathrm{Y}, \mathrm{T}$, and $\mathrm{B}$ indicate the effects of genotype, year (environment), treatment, and blocks nested in years, respectively; and $\varepsilon_{i j k l m}$ is the experimental error associated with $\mathrm{Y}_{\mathrm{ijklm}}$. Correlation analysis and Student's $t$ test were conducted using JMP 10 software (SAS Institute Inc.). All biological sample analyses were conducted in triplicate. The results are presented as means \pm SD based on the three field replicate samples.

\section{Results and Discussion}

Effect of MeJA treatment and variation in environmental conditions on total phenolic and flavonoid concentrations, ABTS, and DPPH antioxidant activities of broccoli floret extracts. Treatment with $250 \mu \mathrm{M} \mathrm{MeJA}$ $4 \mathrm{~d}$ before harvest did not alter total phenolic, kaempferol, or quercetin concentrations, ABTS, or DPPH antioxidant activities in broccoli florets (Table 2). Whereas previous research has reported that MeJA treatment increased total phenolic and flavonoid content in radish and broccoli sprouts (Kim et al., 2006a; Pérez-Balibrea et al., 2011), this was not observed in this study with broccoli florets. The lack of response in our study to MeJA treatment maybe associated with the different tissues evaluated, plant developmental status, or environmental factors. Phenolic and flavonoid biosynthesis in broccoli floret tissue was apparently not influenced by exogenous MeJA application under field conditions.

In this study, year and genotype exerted a significant effect on phytochemical content and antioxidant activity among the broccoli cultivars (Table 2). Total phenolics, quercetin, and kaempferol concentrations in 2010 were 1.9-, 3.0-, and 1.7-fold higher, respectively, in controls than that observed in the 2009 control plants (Table 2). The cultivar
Gypsy showed the highest quercetin concentration fold change (7.5-fold) between 2009 and 2010. Different weather conditions in 2009 and 2010 are presumed to have significantly altered the ratio of quercetin/kaempferol in 'Pirate', 'Imperial', and 'Gypsy'. Antioxidant activity measured by the ABTS and DPPH assays was 1.5- and 2.2-fold higher, respectively, in 2010 than for broccoli harvested in 2009 (Table 2). It has been reported that solar radiation is positively correlated with flavonoid content in broccoli florets (Gliszczynska-Swiglo et al., 2007). Increased total phenolic and flavonoid content in 2010 compared with 2009 may be explained by year-associated weather factors such as solar radiation (Pék et al., 2012). The increased quercetin/kaempferol ratio also maybe a response to increased ultraviolet-B in solar radiation (Kuhlmann and Müller, 2009). Temperature is also known to impact phytochemical content in broccoli florets (Schonhof et al., 2007). The interaction of these various environmental factors on the growth and development of broccoli cultivars likely influenced phytochemical profiles in floret tissue.

Correlation between weather conditions and phytochemical change. From the correlation of extract phytochemical compound concentrations with antioxidant activity and with weather-related environmental growing conditions for each cultivar over 2 years, several meaningful relationships were observed (Table 3). Accumulated GDD, precipitation, and solar radiation for each genotype were associated with DTH. There was a significantly positive correlation between GDD $(r=0.703, P<0.001)$ and solar radiation $(r=$ $0.796, P<0.001)$ with total phenolic concentrations. There were highly significant correlations between tissue ABTS antioxidant

Table 2. Total phenolic and flavonoid concentrations and antioxidant activity of untreated and MeJA-treated broccoli florets over two seasons. ${ }^{\mathrm{z}}$

\begin{tabular}{|c|c|c|c|c|c|c|c|}
\hline Source of variation & Treatment/season & Total phenolics $^{\mathrm{y}}$ & Quercetin $^{\mathrm{x}}$ & Kaempferol $^{\mathrm{x}}$ & $\mathrm{Q} / \mathrm{K}$ ratio $^{\mathrm{w}}$ & $\mathrm{ABTS}^{\mathrm{v}}$ & $\mathrm{DPPH}^{\mathrm{v}}$ \\
\hline \multicolumn{8}{|l|}{ Treatment } \\
\hline & Control & $668 \pm 244$ & $112 \pm 107$ & $63 \pm 26$ & $1.55 \pm 0.76$ & $36.0 \pm 9.8$ & $30.1 \pm 14.8$ \\
\hline & MeJA & $671 \pm 252$ & $117 \pm 92$ & $67 \pm 23$ & $1.59 \pm 0.79$ & $32.7 \pm 9.6$ & $25.8 \pm 13.3$ \\
\hline \multicolumn{8}{|l|}{ Year } \\
\hline 2009 & Control & $463 \pm 108$ & $57 \pm 36$ & $46 \pm 14$ & $1.17 \pm 0.45$ & $28.2 \pm 5.5$ & $18.9 \pm 6.2$ \\
\hline 2010 & Control & $873 \pm 147^{*}$ & $167 \pm 126^{*}$ & $80 \pm 25^{*}$ & $1.93 \pm 0.82 *$ & $43.7 \pm 6.4^{*}$ & $41.3 \pm 12.1^{*}$ \\
\hline \multicolumn{8}{|l|}{ Genotype $^{\mathrm{u}}$} \\
\hline \multirow[t]{2}{*}{ Pirate } & 2009 & $386 \pm 45$ & $51 \pm 7$ & $36 \pm 3$ & $1.44 \pm 0.18$ & $25.4 \pm 3.2$ & $18.2 \pm 5.2$ \\
\hline & 2010 & $942 \pm 3 *$ & $139 \pm 27 *$ & $62 \pm 10^{*}$ & $2.25 \pm 0.22 *$ & $40.0 \pm 3.3^{*}$ & $39.5 \pm 1.4^{*}$ \\
\hline \multirow{2}{*}{ Expo } & 2009 & $524 \pm 28$ & $37 \pm 23$ & $43 \pm 10$ & $0.83 \pm 0.35$ & $30.7 \pm 1.4$ & $21.1 \pm 1.9$ \\
\hline & 2010 & $800 \pm 42 *$ & $81 \pm 9^{*}$ & $61 \pm 7$ & $1.34 \pm 0.16$ & $45.0 \pm 4.0 *$ & $37.4 \pm 1.2 *$ \\
\hline \multirow[t]{2}{*}{ Green Magic } & 2009 & $631 \pm 71$ & $115 \pm 34$ & $69 \pm 13$ & $1.65 \pm 0.19$ & $34.9 \pm 3.8$ & $25.5 \pm 5.5$ \\
\hline & 2010 & $820 \pm 42 *$ & $133 \pm 5$ & $87 \pm 4$ & $1.52 \pm 0.02$ & $38.0 \pm 3.3$ & $33.5 \pm 2.5$ \\
\hline \multirow[t]{2}{*}{ Imperial } & 2009 & $391 \pm 13$ & $25 \pm 12$ & $40 \pm 2$ & $0.62 \pm 0.30$ & $23.3 \pm 5.7$ & $11.2 \pm 6.3$ \\
\hline & 2010 & $701 \pm 40^{*}$ & $78 \pm 3^{*}$ & $66 \pm 10^{*}$ & $1.20 \pm 0.13 *$ & $42.9 \pm 6.5^{*}$ & $32.2 \pm 1.3^{*}$ \\
\hline \multirow[t]{2}{*}{ Gypsy } & 2009 & $385 \pm 17$ & $54 \pm 10$ & $41 \pm 7$ & $1.31 \pm 0.16$ & $26.9 \pm 5.4$ & $18.6 \pm 3.4$ \\
\hline & 2010 & $1104 \pm 55^{*}$ & $405 \pm 8^{*}$ & $122 \pm 2 *$ & $3.32 \pm 0.12 *$ & $52.7 \pm 3.1 *$ & $63.9 \pm 2.6^{*}$ \\
\hline
\end{tabular}

${ }^{\mathrm{z}}$ The results are presented as means $\pm \mathrm{SD}(\mathrm{n}=3)$. Three analytical replications were conducted for each biological sample. Student's $t$-tests were conducted to determine significance at $P \leq 0.05$. MeJA treatment groups are not presented here because they were not significantly different from control groups.

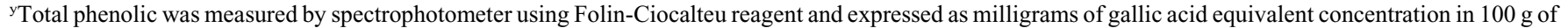
freeze-dried broccoli powder.

${ }^{x}$ Flavonoids were measured by high-performance liquid chromatography and expressed as $\mu$ mol/100 g of freeze-dried broccoli powder.

${ }^{\text {w }}$ Ratio of quercetin to kaempferol concentrations.

${ }^{\mathrm{v}}$ Antioxidant activities are presented as Trolox equivalent concentration ( $\mathrm{mmol} / 100 \mathrm{~g}$ of freeze-dried broccoli powder).

"Values presented for individual genotype are untreated controls. Asterisks indicate means that are significantly different based on the Student's $t$-test between treatments or different years within same genotypes $(P \leq 0.05)$.

MeJa = methyl jasmonate; ABTS = 2,2'-azino-bis(3-ethylbenzothiazoline-6-sulphonic acid) diammonium salt; DPPH = 2,2-diphenyl-1-picrylhydrazyl. 
Table 3. Correlation between accumulated weather factors and phytochemicals and antioxidant activities. ${ }^{\mathrm{z}}$

\begin{tabular}{|c|c|c|c|c|c|c|c|c|c|}
\hline & $\mathrm{DTH}^{\mathrm{y}}$ & $\mathrm{GDD}^{\mathrm{x}}$ & Precipitation/DTH & Solar radiation & $\mathrm{TPC}^{\mathrm{w}}$ & ABTS & DPPH & Quercetin & Kaempferol \\
\hline$\overline{\mathrm{DTH}}$ & 1.000 & & & & & & & & \\
\hline GDD & $0.893 * * *$ & 1.000 & & & & & & & \\
\hline Precipitation/DTH & $-0.701 * * *$ & $-0.800 * * *$ & 1.000 & & & & & & \\
\hline Solar radiation & $0.773 * * *$ & $0.974 * * *$ & $-0.774 * * *$ & 1.000 & & & & & \\
\hline TPC & 0.388 & $0.703 * * *$ & $-0.620 * *$ & $0.796 * * *$ & 1.000 & & & & \\
\hline ABTS & 0.344 & $0.644 * * *$ & $-0.518^{*}$ & $0.747 * * *$ & $0.927 * * *$ & 1.000 & & & \\
\hline DPPH & 0.344 & $0.630 * * *$ & $-0.539 *$ & $0.719 * * *$ & $0.934 * * *$ & $0.953 * * *$ & 1.000 & & \\
\hline Quercetin & -0.019 & 0.260 & -0.261 & 0.360 & $0.769 * * *$ & $0.728 * * *$ & $0.860 * * *$ & 1.000 & \\
\hline Kaempferol & 0.002 & 0.304 & -0.197 & 0.420 & $0.803 * * *$ & $0.785 * * *$ & $0.830 * * *$ & $0.868 * * *$ & \\
\hline $\mathrm{Q} / \mathrm{K}$ ratio $^{\mathrm{v}}$ & 0.067 & 0.322 & -0.327 & 0.403 & $0.721 * * *$ & $0.635 * * *$ & $0.803 * * *$ & $0.935 * * *$ & $0.710 * * *$ \\
\hline
\end{tabular}

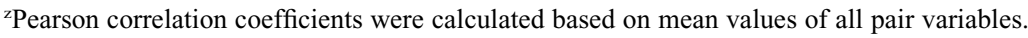

${ }^{y} \mathrm{DTH}=$ number of days from transplant to harvest.

${ }^{\mathrm{x}} \mathrm{GDD}=$ growing degree-days.

${ }^{\mathrm{w}} \mathrm{TPC}=$ total phenol content.

'Ratio of quercetin to kaempferol concentrations.

Means with *,**, and *** indicate significance based on the two-tailed Pearson correlation test at $P \leq 0.05, P \leq 0.01$, and $P \leq 0.001$, respectively.

ABTS = 2,2'-azino-bis(3-ethylbenzothiazoline-6-sulphonic acid) diammonium salt; DPPH = 2,2-diphenyl-1-picrylhydrazyl.

activity with total phenolics $(r=0.927, P<$ $0.001)$, quercetin $(r=0.728, P<0.001)$, and kaempferol $(r=0.785, P<0.001)$ concentrations (Table 3 ). There were also highly significant correlations between tissue DPPH antioxidant activity with total phenolics $(r=$ $0.934, P<0.001)$, quercetin $(r=0.860, P<$ $0.001)$, and kaempferol $(r=0.830, P<$ 0.001). Because ABTS, DPPH, and total phenolics are based on an electron transfer antioxidant assay, linear correlations are often observed between these antioxidant assays and total phenolics (Huang et al., 2005). Eberhardt et al. (2005) have also reported that oxygen radical absorbance capacity assay showed a significant correlation with the total phenolic content of hydrophilic broccoli extracts.

As was previously observed by Pék et al. (2013), total phenolic content was negatively correlated with precipitation/DTH, which is averaged precipitation per day after transplanting $(r=-0.620, P<0.004)$ (Table 3$)$. Because we only applied irrigation at the time of transplanting seedlings, limitations in soil water availability in 2010 may have led to increased total phenolics, which is associated with antioxidant activity in broccoli. Water deprivation at flowering and during pod fill in Brassica napus has been associated with increased phenolic content in rapeseed (Bouchereau et al., 1996). Unlike previous reports, there was only a weak correlation between solar radiation and flavonoid (quercetin $r=0.360, P=0.120$; kaempferol $r=0.420$, $P=0.065$ ) concentrations (GliszczynskaSwiglo et al., 2007). In addition, the ratio of quercetin to kaempferol tended to weakly correlate with solar radiation but was not significant ( $r=0.403, P=0.078)$.

Partitioning of broccoli phytochemical concentrations and antioxidant activity variances into MeJA treatment, year, and genotype sources of variation. Analysis of variance partitioning of the variances for phytochemical concentrations indicated that differences among broccoli genotypes described $34 \%$ and $15 \%$ of the total variation for kaempferol and quercetin, respectively, whereas there was no significant MeJA effect (Table 4). Seasonal differences in

Table 4. Percentages of total variance described by main factors (genotype, treatment, year) and factor interactions for broccoli floret phytochemical concentrations and bioactivities.

\begin{tabular}{lccccc}
\hline & Total phenolics $^{\mathrm{z}}$ & Quercetin $^{\mathrm{y}}$ & Kaempferol $^{\mathrm{y}}$ & ABTS $^{\mathrm{x}}$ & DPPH $^{\mathrm{x}}$ \\
\hline Genotype (G) & $6.5^{* * *}$ & $14.9^{* * *}$ & $33.6^{* * *}$ & $6.9^{* * *}$ & $14.3^{* * *}$ \\
Treatment (T) & 0.0 & 0.9 & 0.1 & 2.9 & 2.0 \\
Year (Y) & $74.0^{* * *}$ & $23.9^{* * *}$ & $33.5^{* * *}$ & $64.8^{* * *}$ & $61.2^{* * *}$ \\
G $\times$ T & 0.4 & 4.8 & 0.3 & 0.6 & 1.2 \\
G $\times$ Y & $12.2^{* * *}$ & $36.5^{* * *}$ & $28.4 * * *$ & $9.5^{* * *}$ & $11.9^{* * *}$ \\
T $\times$ Y & 0.0 & 0.9 & 0.0 & 0.0 & 0.0 \\
G $\times$ T $\times$ Y & 2.5 & 4.3 & 1.1 & 4.0 & 2.0 \\
Block (year) & 0.4 & 0.5 & 0.2 & 1.1 & 0.5 \\
Residual & 4.0 & 13.3 & 2.8 & 10.0 & 6.6 \\
$R^{2 \mathrm{w}}$ & 0.96 & 0.97 & 0.86 & 0.90 & 0.93 \\
\hline
\end{tabular}

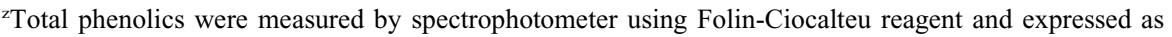
milligrams of gallic acid equivalent concentration in $100 \mathrm{~g}$ of freeze-dried broccoli powder.

${ }^{y}$ Flavonoids were measured by high-performance liquid chromatography and expressed as $\mu \mathrm{mol} / 100 \mathrm{~g}$ of freeze-dried broccoli powder.

${ }^{\mathrm{x}}$ Antioxidant activities are presented as Trolox equivalent concentration $(\mathrm{mmol} / 100 \mathrm{~g}$ of freeze-dried broccoli powder).

${ }^{\mathrm{w}}$ Fraction of total variance described by the regression.

**** indicates factor that describes a significant proportion of the total variance using analysis of variance at $P \leq 0.001$ (two-tailed test).

ABTS = 2,2'-azino-bis(3-ethylbenzothiazoline-6-sulphonic acid) diammonium salt; $\mathrm{DPPH}=2,2-$ diphenyl-1-picrylhydrazyl.

environmental conditions between 2009 and 2010 were a major source of variation in total phenolic $(74 \%)$, quercetin $(24 \%)$, and kaempferol (34\%) concentrations and in the ABTS (66\%) and DPPH (62\%) antioxidant activity of floret extracts (Table 4). There were also significant genotype-by-year interactions on total phenolics $(12 \%, P<$ 0.001 ), flavonoids (quercetin, $37 \%, P=$ 0.001 ; kaempferol, 28\%, $P<0.001$ ), and antioxidant activity (ABTS, $10 \%, P=0.001$; DPPH, $12 \%, P<0.001$ ) (Table 4 ). Broccoli harvest maturity differed among hybrids with the days to harvest interacting with environmental factors associated with the accumulation of total phenolics. The genotype described the largest component of variance $(75 \%)$ for DTH (data not shown). DTH played a major role in accumulation of phytochemicals through the interaction with environmental conditions in cultivars with varying maturities. A large portion of the year effects on variation in total phenolic, quercetin, and kaempferol concentrations and in the ABTS and DPPH activities are associated with a genotype-by-environment interaction. These results suggest that appropriate cultivar selection or breeding for adaptation to certain environment conditions can maximize phenolics and antioxidant bioactivity of broccoli florets. With appropriate parental material and selection schemes, it may be feasible to achieve high flavonoid and phenolic content in shorter maturing varieties as was previously reported for the development of higher glucosinolate (glucoraphanin) content in early-maturing broccoli germplasm (Farnham et al., 2004).

MeJA effect on kale leaf sample extracts. Unlike broccoli heads, growers harvest kale leaf tissue repeatedly during the growing season. These harvests consist primarily of apical leaf tissues for commercial consumption, which are young and tender (Velasco et al., 2007). Thus, we evaluated two different leaf tissue maturities from the two different kale cultivars. The MeJA treatment significantly increased total phenolics and antioxidant activity in both kale species in both years (Table 5). The increase in leaf phenolic content varied among genotypes, years, and apical or basal leaf samples. MeJA 
Table 5. Total phenolic and flavonoid concentrations and antioxidant activity of untreated and MeJA-treated kale leaf samples over two seasons. ${ }^{\mathrm{z}}$

\begin{tabular}{|c|c|c|c|c|c|c|}
\hline Source of variation & Treatment/season & Total phenolics ${ }^{\mathrm{y}}$ & Quercetin $^{\mathrm{x}}$ & Kaempferol $^{\mathrm{x}}$ & $\mathrm{ABTS}^{\mathrm{w}}$ & $\mathrm{DPPH}^{\mathrm{w}}$ \\
\hline \multicolumn{7}{|l|}{ Apical tissue } \\
\hline \multicolumn{7}{|l|}{ Treatment } \\
\hline & Control & $1545 \pm 219$ & $153 \pm 91$ & $154 \pm 50$ & $4932 \pm 433$ & $3811 \pm 308$ \\
\hline & MeJA & $1962 \pm 282 * * *$ & $237 \pm 139$ & $176 \pm 36$ & $5571 \pm 299 * * *$ & $4985 \pm 299^{*}$ \\
\hline \multicolumn{7}{|l|}{ Year } \\
\hline \multirow[t]{2}{*}{2010} & Control & $1653 \pm 225$ & $120 \pm 72$ & $177 \pm 24$ & $5130 \pm 406$ & $3476 \pm 1167$ \\
\hline & MeJA & $2188 \pm 132 * * *$ & $241 \pm 147$ & $169 \pm 29$ & $5778 \pm 155^{* *}$ & $4229 \pm 711$ \\
\hline \multirow[t]{2}{*}{2011} & Control & $1438 \pm 165$ & $186 \pm 102$ & $131 \pm 61$ & $4734 \pm 393$ & $4148 \pm 1682$ \\
\hline & MeJA & $1735 \pm 185^{*}$ & $232 \pm 145$ & $182 \pm 45$ & $5365 \pm 265^{* *}$ & $5741 \pm 1232$ \\
\hline \multicolumn{7}{|l|}{ Genotype } \\
\hline \multirow{3}{*}{ Dwarf Blue Curled Vates } & (2010) & & & & & \\
\hline & Control & $1846 \pm 113$ & $184 \pm 34$ & $165 \pm 25$ & $5488 \pm 68$ & $4533 \pm 214$ \\
\hline & MeJA & $2298 \pm 50^{* *}$ & $373 \pm 27 * *$ & $152 \pm 11$ & $5911 \pm 56^{* *}$ & $4819 \pm 359$ \\
\hline \multirow[t]{2}{*}{ Red Winter } & Control & $1461 \pm 48$ & $58.2 \pm 7.7$ & $190 \pm 17$ & $4770 \pm 144$ & $2419 \pm 77$ \\
\hline & $\begin{array}{l}\text { MeJA } \\
(2011)\end{array}$ & $2079 \pm 73 * * *$ & $109 \pm 26^{*}$ & $186 \pm 33$ & $5645 \pm 64 * * *$ & $3639 \pm 100 * * *$ \\
\hline \multirow[t]{2}{*}{ Dwarf Blue Curled Vates } & Control & $1579 \pm 76$ & $278 \pm 19$ & $129 \pm 13$ & $5088 \pm 84$ & $5319 \pm 561$ \\
\hline & MeJA & $1825 \pm 111^{*}$ & $363 \pm 22 * *$ & $143 \pm 8$ & $5545 \pm 55^{* *}$ & $5633 \pm 592$ \\
\hline \multirow[t]{2}{*}{ Red Winter } & Control & $1296 \pm 42$ & $93.8 \pm 12$ & $133 \pm 95$ & $4380 \pm 48$ & $2662 \pm 315$ \\
\hline & MeJA & $1644 \pm 121 *$ & $101 \pm 10$ & $222 \pm 15$ & $5184 \pm 274 * *$ & $4908 \pm 634^{*}$ \\
\hline \multicolumn{7}{|l|}{ Basal tissue } \\
\hline \multicolumn{7}{|l|}{ Treatment } \\
\hline & Control & $1242 \pm 133$ & $97.8 \pm 67.8$ & $124 \pm 33$ & $4189 \pm 308$ & $2484 \pm 308$ \\
\hline & MeJA & $1342 \pm 172$ & $87.7 \pm 49.1$ & $132 \pm 33$ & $4599 \pm 353^{* *}$ & $2707 \pm 353$ \\
\hline \multicolumn{7}{|l|}{ Year } \\
\hline \multirow[t]{2}{*}{2010} & Control & $1245 \pm 142$ & $73.0 \pm 36$ & $112 \pm 37$ & $4031 \pm 314$ & $2117 \pm 249$ \\
\hline & MeJA & $1370 \pm 229$ & $106 \pm 55$ & $118 \pm 38$ & $4502 \pm 413$ & $2316 \pm 422$ \\
\hline \multirow[t]{2}{*}{2011} & Control & $1240 \pm 138$ & $123 \pm 86$ & $138 \pm 25$ & $4346 \pm 225$ & $2850 \pm 559$ \\
\hline & MeJA & $1314 \pm 102$ & $69.0 \pm 38$ & $146 \pm 20^{*}$ & $4696 \pm 284^{*}$ & $3098 \pm 404$ \\
\hline \multicolumn{7}{|l|}{ Genotype } \\
\hline \multirow{3}{*}{ Dwarf Blue Curled Vates } & (2010) & & & & & \\
\hline & Control & $1366 \pm 11$ & $90.0 \pm 46$ & $124 \pm 33$ & $4310 \pm 87$ & $2286 \pm 223$ \\
\hline & MeJA & $1575 \pm 52 * *$ & $154 \pm 19$ & $145 \pm 6.0$ & $4836 \pm 248^{*}$ & $2676 \pm 203$ \\
\hline \multirow[t]{2}{*}{ Red Winter } & Control & $1123 \pm 75$ & $56.0 \pm 16$ & $99.5 \pm 43$ & $3753 \pm 85$ & $1949 \pm 142$ \\
\hline & $\begin{array}{l}\text { MeJA } \\
(2011)\end{array}$ & $1165 \pm 54$ & $59.0 \pm 22$ & $90.7 \pm 37$ & $4169 \pm 175^{*}$ & $1956 \pm 125$ \\
\hline \multirow[t]{2}{*}{ Dwarf Blue Curled Vates } & Control & $1348 \pm 110$ & $198 \pm 37^{*}$ & $160 \pm 4.9^{*}$ & $4509 \pm 199$ & $3248 \pm 423$ \\
\hline & MeJA & $1399 \pm 46$ & $87.1 \pm 51$ & $133 \pm 14.2$ & $4826 \pm 307$ & $3067 \pm 595$ \\
\hline \multirow[t]{2}{*}{ Red Winter } & Control & $1133 \pm 29$ & $47.7 \pm 8.5$ & $116 \pm 3.8$ & $4183 \pm 86$ & $2452 \pm 335$ \\
\hline & MeJA & $1231 \pm 55$ & $50.9 \pm 7.4$ & $159 \pm 18.5^{*}$ & $4566 \pm 237$ & $3129 \pm 227 *$ \\
\hline
\end{tabular}

${ }^{z}$ The results are presented as means $\pm \mathrm{SD}(\mathrm{n}=3)$. Three analytical replications were conducted for each biological sample. Student's $t$-tests were conducted to determine significance at $* ; P<0.05, * * ; P<0.01$, and $* * * ; P<0.001$.

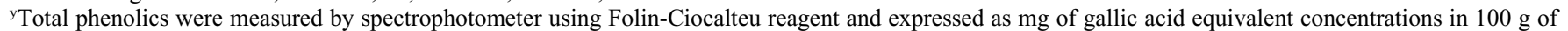
freeze-dried kale powder.

${ }^{\mathrm{x}}$ Flavonoids were measured by high-performance liquid chromatography and expressed as $\mu \mathrm{mol} / 100 \mathrm{~g}$ of freeze-dried kale powder.

${ }^{\mathrm{w}}$ Antioxidant activities are presented as Trolox equivalent concentration ( $\mathrm{mmol} / 100 \mathrm{~g}$ of freeze-dried kale powder).

MeJa = methyl jasmonate; ABTS = 2,2'-azino-bis(3-ethylbenzothiazoline-6-sulphonic acid) diammonium salt; DPPH = 2,2-diphenyl-1-picrylhydrazyl.

treatments were observed to interact with leaf age where apical leaf tissue, which is the primary commercial product consumed by the public, was more responsive to treatments in terms of increases in total phenolics, quercetin, and ABTS antioxidant activity than basal leaf tissue. MeJA response also varied between years, which may be associated with the different weather conditions observed in 2010 and 2011. Because kale leaf harvests were conducted on the same date and each genotype experienced approximately the same number of GDDs in both years, the primary weather factor that differed between years was precipitation. Our kale plots in July 2011 received only 44\% of precipitation the plots received in July 2010. Water deprivation at flowering and during pod fill in Brassica napus has been associated with increased phenolic content in rapeseed (Bouchereau et al., 1996). Another study also reported that water stress increased phenolic compounds in lettuce (Oh et al., 2010). Endogenous jasmonic acid has been observed to accumulate in planta under drought conditions (Creelman and Mullet, 1995). Thus, conditions in 2011 may have led to the accumulation of endogenous jasmonate, which could have attenuated the effect of exogenous MeJA treatment.

Although the physiological relationship between antioxidant compounds and human health-promoting activity has not been thoroughly established, consumers have indicated their willingness to pay a premium for produce with high nutritional value and antioxidant activity (i.e., melons with $25 \%$ more vitamin C) (Bond et al., 2008). Previous research reported that MeJA treatment increased the dietary impact of various crops on quinone reductase, antioxidant, antiproliferative, and antiadipogenic activity as measured by the effect of extracts on cultured mammalian cells (Kim et al., 2006b; Ku et al., 2013; Lee et al., 2013; Wang et al., 2008). This study showed that MeJA could enhance levels of antioxidant phytochemicals and antioxidant activity in kale leaf tissues. It may be feasible to develop brassica vegetables with enhanced consumer healthpromoting properties, but the magnitude of this effect may be attenuated by interaction with biotic and abiotic stress conditions in the growing environment (Mewis et al., 2012).

Partitioning of kale phytochemical concentrations and antioxidant activity variances into MeJA treatment, year, and genotype sources of variation. Analysis of variance partitioning of the variances for phytochemical concentrations indicated that differences among genotypes described $28 \%$ and $18 \%$ of the total variation for total phenolic and ABTS antioxidant activity in kale apical leaf tissue, respectively (Table 6). In addition, MeJA treatment described 18\%, 76\%, $29 \%$, and $41 \%$ of the total variation for total phenolic and quercetin concentrations and ABTS and DPPH antioxidant activity in kale apical leaf tissue, respectively (Table 6), whereas no significant MeJA effect was observed on phytochemical content and antioxidant activity in broccoli floret tissue (Table 4). 
Table 6. Percentages of total variance described by main factors (genotype, treatment, year) and factor interactions for kale leaves phytochemical concentrations and antioxidant activities.

\begin{tabular}{|c|c|c|c|c|c|}
\hline & Total phenolics ${ }^{\mathrm{z}}$ & Quercetin $^{\mathrm{y}}$ & Kaempferol $^{\mathrm{y}}$ & $\operatorname{ABTS}^{x}$ & $\mathrm{DPPH}^{\mathrm{x}}$ \\
\hline \multicolumn{6}{|l|}{ Apical tissue } \\
\hline Genotype (G) & $27.5^{* * *}$ & 1.4 & 3.7 & $17.8 * * *$ & 9.7 \\
\hline Treatment $(\mathrm{T})$ & $17.5^{* * *}$ & $76.2 * * *$ & 16.8 & $28.7 * * *$ & $41.0 * * *$ \\
\hline Year (Y) & $42.5 * * *$ & $12.1 * * *$ & 6.2 & $44.6 * * *$ & 11.7 \\
\hline $\mathrm{G} \times \mathrm{T}$ & 0.3 & 0.3 & 0.5 & 0.0 & 0.0 \\
\hline $\mathrm{G} \times \mathrm{Y}$ & 1.1 & $5.2 * * *$ & 5.7 & $4.4 * * *$ & 12.1 \\
\hline $\mathrm{T} \times \mathrm{Y}$ & 3.5 & $2.4 * * *$ & 12.0 & 0.0 & 0.2 \\
\hline $\mathrm{G} \times \mathrm{T} \times \mathrm{Y}$ & 0.1 & 0.4 & 3.8 & 0.1 & 2.8 \\
\hline Block (year) & 2.0 & 1.1 & 1.4 & 1.4 & 2.1 \\
\hline Residual & 5.5 & 1.0 & 50.0 & 3.0 & 20.3 \\
\hline$R^{2 \mathrm{w}}$ & 0.94 & 0.99 & 0.50 & 0.97 & 0.80 \\
\hline \multicolumn{6}{|l|}{ Basal tissue } \\
\hline Genotype & 0.9 & 0.3 & 18.5 & 11.3 & $47.0 * * *$ \\
\hline Treatment & $69.3 * * *$ & $47.8 * * *$ & 15.2 & $35.8 * * *$ & 16.4 \\
\hline Year & $10.3 * * *$ & 0.8 & 1.3 & $29.6 * * *$ & 4.1 \\
\hline $\mathrm{G} \times \mathrm{T}$ & 4.7 & 1.6 & 5.7 & 4.5 & 0.5 \\
\hline $\mathrm{G} \times \mathrm{Y}$ & 0.9 & 1.4 & 2.6 & 0.0 & 1.2 \\
\hline $\mathrm{T} \times \mathrm{Y}$ & 0.7 & 14.7 & 0.0 & 0.6 & 0.0 \\
\hline $\mathrm{G} \times \mathrm{T} \times \mathrm{Y}$ & 3.0 & 14.7 & 15.8 & 0.3 & 7.9 \\
\hline Block (year) & 0.7 & 0.8 & 2.0 & 0.8 & 0.9 \\
\hline Residual & 9.5 & 18.0 & 39.0 & 17.0 & 21.9 \\
\hline$R^{2 \mathrm{w}}$ & 0.90 & 0.82 & 0.61 & 0.83 & 0.78 \\
\hline
\end{tabular}

****indicates factor that describes a significant proportion of the total variance using analysis of variance at $P \leq 0.001$ (two tailed-test).

${ }^{z}$ Total phenolics were measured by spectrophotometer using Folin-Ciocalteu reagent and expressed as mg of gallic acid equivalent concentration in $100 \mathrm{~g}$ of freeze-dried kale powder.

${ }^{\mathrm{y}}$ Flavonoids were measured by high-performance liquid chromatography and expressed as $\mu \mathrm{mol} / 100 \mathrm{~g}$ of freeze-dried kale powder.

${ }^{\mathrm{x}}$ Antioxidant activities are presented as Trolox equivalent concentration $(\mathrm{mmol} / 100 \mathrm{~g}$ of freeze-dried kale powder)

${ }^{\mathrm{w}}$ Fraction of total variance described by the regression.

ABTS = 2,2'-azino-bis(3-ethylbenzothiazoline-6-sulphonic acid) diammonium salt; DPPH = 2,2diphenyl-1-picrylhydrazyl.

Seasonal differences in environmental conditions between 2010 and 2011 explained a significant portion of the variance for total phenolics, quercetin, and ABTS antioxidant activity in kale apical tissue and basal tissue, but the portion was smaller in basal leaf tissue.

MeJA treatment of broccoli inflorescence and kale leaf tissue appears to be a tissuespecific response. Kim and Juvik (2011) reported MeJA treatment under greenhouse conditions significantly increased glucosinolate concentrations in broccoli florets but had no effect on phenolic and flavonoid concentrations. Under biotic or abiotic stress, plants tend to accumulate defense compounds in vulnerable tissues such as young leaves or florets (Dam et al., 1996; Zangerl and Bazzaz, 1992). Accumulation of different defense compounds in plants is tissue-specific and preferentially allocated to plant parts that promote plant fitness and survival that are at risk of attack from herbivores (Zangerl and Bazzaz, 1992). Because the photosynthetic capacity of leaves declines with age, young leaf tissue plays a critical role in survival and thus would show a more dramatic response to MeJA treatment. Previous studies have reported that the youngest leaves of the rosette plants of Cynoglossum officinale contain 50 to 190 times higher concentrations of pyrrolizidine alkaloid than old leaves and that the compound acts as a defense against generalist herbivores (Dam et al., 1996). In kale, MeJA treatment increased not only flavonoids and
Bond, C.A., D. Thilmany, and J. Keeling Bond. 2008. Understanding consumer interest in product and process-based attributes for fresh produce. Agribusiness 24:231-252.

Bouchereau, A., N. Clossais-Besnard, A. Bensaoud, L. Leport, and M. Renard. 1996. Water stress effects on rapeseed quality. Eur. J. Agron. 5:19-30.

Cai, Y., Q. Luo, M. Sun, and H. Corke. 2004. Antioxidant activity and phenolic compounds of 112 traditional Chinese medicinal plants associated with anticancer. Life Sci. 74:21572184.

Creelman, R.A. and J.E. Mullet. 1995. Jasmonic acid distribution and action in plants: Regulation during development and response to biotic and abiotic stress. Proc. Natl. Acad. Sci. USA 92:4114-4119.

Dam, N.M.V., T.J.D. Jong, Y. Iwasa, and T. Kubo. 1996. Optimal distribution of defences: Are plants smart investors? Funct. Ecol. 10:128136.

Dimitrios, B. 2006. Sources of natural phenolic antioxidants. Trends in Food Sci. \&. Tech. 17:505-512.

Dufault, R.J. 1997. Determining heat unit requirements for broccoli harvest in coastal South Carolina. J. Amer. Soc. Hort. Sci. 122:169-174.

Eberhardt, M.V., K. Kobira, A.S. Keck, J.A. Juvik, and E.H. Jeffery. 2005. Correlation analyses of phytochemical composition, chemical, and cellular measures of antioxidant activity of broccoli (Brassica oleracea L. var. italica). J. Agr. Food Chem. 53:7421-7431.

Farnham, M.W., P.E. Wilson, K.K. Stephenson, and J.W. Fahey. 2004. Genetic and environmental effects on glucosinolate content and chemoprotective potency of broccoli. Plant Breed. 123:60-65.

Gates, M.A., S.S. Tworoger, J.L. Hecht, I. De Vivo, B. Rosner, and S.E. Hankinson. 2007. A prospective study of dietary flavonoid intake and incidence of epithelial ovarian cancer. Intl. J. Cancer 121:2225-2232.

Gliszczynska-Swiglo, A., A. Kaluzewicz, K. Lemanska, M. Knaflewski, and B. Tyrakowska. 2007. The effect of solar radiation on the flavonol content in broccoli inflorescence. Food Chem. 100:241-245.

Hopkins, R.J., N.M. van Dam, and J.J. van Loon. 2009. Role of glucosinolates in insect-plant relationships and multitrophic interactions. Annu. Rev. Entomol. 54:57-83.

Huang, D., B. Ou, and R.L. Prior. 2005. The chemistry behind antioxidant capacity assays. J. Agr. Food Chem. 53:1841-1856.

Khan, M.A.M., C. Ulrichs, and I. Mewis. 2011. Effect of water stress and aphid herbivory on flavonoids in broccoli (Brassica oleracea var. italica Plenck). J. Appl. Bot. \& Food Quality. 84:178-182.

Kim, H.J., F. Chen, X. Wang, and J.H. Choi. 2006a. Effect of methyl jasmonate on phenolics, isothiocyanate, and metabolic enzymes in radish sprout (Raphanus sativus L.). J. Agr. Food Chem. 54:7263-7269.

\section{Literature Cited}

Alam, M.A., C. Sernia, and L. Brown. 2013. Ferulic acid improves cardiovascular and kidney structure and function in hypertensive rats. J. Cardiovasc. Pharmacol. 61:240-249.

Björkman, M., I. Klingen, A.N.E. Birch, A.M. Bones, T.J.A. Bruce, T.J. Johansen, R. Meadow, J. Mølmanne, R. Seljåsen, L.E. Smart, and D. Stewart. 2011. Phytochemicals of Brassicaceae in plant protection and human health, influences of climate, environment and agronomic practice. Phytochem. 72:538-556.
Kim, H.J., F. Chen, X. Wang, and N.C. Rajapakse. 2006b. Effect of methyl jasmonate on secondary metabolites of sweet basil (Ocimum basilicum L.). J. Agr. Food Chem. 54:23272332.

Kim, H.J., K.J. Park, and J.H. Lim. 2011. Metabolomic analysis of phenolic compounds in buckwheat (Fagopyrum esculentum M.) sprouts treated with methyl jasmonate. J. Agr. Food Chem. 59:5707-5713.

Kim, H.S. and J.A. Juvik. 2011. Effect of selenium fertilization and methyl jasmonate treatment on 
glucosinolate accumulation in broccoli florets. J. Amer. Soc. Hort. Sci. 136:239-246.

Koh, E., K.M.S. Wimalasiri, A.W. Chassy, and A.E. Mitchell. 2009. Content of ascorbic acid, quercetin, kaempferol and total phenolics in commercial broccoli. J. Food Compost. Anal. 22:637-643.

Ku, K.M., J.N. Choi, J. Kim, J.K. Kim, L.G. Yoo, S.J. Lee, Y.S. Hong, and C.H. Lee. 2010. Metabolomics analysis reveals the compositional differences of shade grown tea (Camellia sinensis L.). J. Agr. Food Chem. 58:418 426.

Ku, K.M. and J.A. Juvik. 2012. Optimum methyl jasmonate application to enhance glucosinolate concentration in broccoli florets. HortScience 47:S311 (abstr.).

Ku, K.M., J.H. Choi, M.M. Kushad, E.H. Jeffery, and J.A. Juvik. 2013. Pre-harvest methyl jasmonate treatment enhances cauliflower chemoprotective attributes without a loss in postharvest quality. Plant Foods Hum. Nutr. 68: $113-117$.

Ku, K.M. and J.A. Juvik. 2012. Optimum methyl jasmonate application to enhance glucosinolate concentration in broccoli florets. HortScience 47:S311 (abstr.).

Kuhlmann, F. and C. Müller. 2009. Independent responses to ultraviolet radiation and herbivore attack in broccoli. J. Expt. Bot. 60:3467-3475.

Kurilich, A.C., E.H. Jeffery, J.A. Juvik, M.A. Wallig, and B.P. Klein. 2002. Antioxidant capacity of different broccoli (Brassica oleracea) genotypes using the oxygen radical absorbance capacity (ORAC) assay. J. Agr. Food Chem. 50:5053-5057.

Larson, A.J., J.D. Symons, and T. Jalili. 2012. Therapeutic potential of quercetin to decrease blood pressure: Review of efficacy and mechanisms. Adv. Nutr. 3:39-46.

Lee, Y.J., K.J. Kim, K.J. Park, B.R. Yoon, J.H. Lim, and O.H. Lee. 2013. Buckwheat (Fagopyrum esculentum $\mathrm{M}$.) sprout treated with methyl jasmonate (MeJA) improved antiadipogenic activity associated with the oxidative stress system in 3T3-L1 adipocytes. Intl. J. Mol. Sci. 14:1428-1442.

Mewis, I., M. Schreiner, C.N. Nguyen, A. Krumbein, C. Ulrichs, M. Lohse, and R. Zrenner. 2012. UV-B irradiation changes specifically the secondary metabolite profile in broccoli sprouts: Induced signaling overlaps with defense response to biotic stressors. Plant Cell Physiol. 53:1546-1560.

Moon, J., S.M. Lee, H.J. Do, Y. Cho, J.H. Chung, and M.J. Shin. 2012. Quercetin up-regulates LDL receptor expression in HepG2 cells. Phytother. Res. 26:1688-1694.

Moon, J.K. and T. Shibamoto. 2009. Antioxidant assays for plant and food components. J. Agr. Food Chem. 57:1655-1666.

Moon, Y.J., X. Wang, and M.E. Morris. 2006. Dietary flavonoids: Effects on xenobiotic and carcinogen metabolism. Toxicol. In Vitro 20:187-210.

Murakami, A., H. Ashida, and J. Terao. 2008 Multitargeted cancer prevention by quercetin. Cancer Lett. 269:315-325.

Neuhouser, M.L. 2004. Dietary flavonoids and cancer risk: Evidence from human population studies. Nutr. Cancer 50:1-7.

Nothlings, U., S.P. Murphy, L.R. Wilkens, B.E. Henderson, and L.N. Kolonel. 2007. Flavonols and pancreatic cancer risk: The multiethnic cohort study. Amer. J. Epidemiol. 166:924-931.

Oh, M.M., E.E. Carey, and C.B. Rajashekar. 2010. Regulated water deficits improve phytochemical concentration in lettuce. J. Amer. Soc. Hort. Sci. 135:223-229.

Pék, Z., H. Daood, M.G. Nagyné, M. Berki, M. Tóthné Márkus, A. Neményi, and L. Helyes. 2012. Yield and phytochemical compounds of broccoli as affected by temperature, irrigation, and foliar sulfur supplementation. HortScience 47:1646-1652.

Pék, Z., H. Daood, M.G. Nagyné, A. Neményi, and L. Helyes. 2013. Effect of environmental conditions and water status on the bioactive compounds of broccoli. Central European J. Biol. 8:777-787.
Pérez-Balibrea, S., D.A. Moreno, and C. GarcíaViguera. 2011. Improving the phytochemical composition of broccoli sprouts by elicitation. Food Chem. 129:35-44.

Poulsen, H.E., H. Prieme, and S. Loft. 1998. Role of oxidative DNA damage in cancer initiation and promotion. Eur. J. Cancer Prev. 7:9-16.

Schonhof, I., H.P. Kläring, A. Krumbein, W. Claußen, and M. Schreiner. 2007. Effect of temperature increase under low radiation conditions on phytochemicals and ascorbic acid in greenhouse grown broccoli. Agr. Ecosystems \& Environ. 119:103-111.

Suzuki, A., N. Yamamoto, H. Jokura, M. Yamamoto, A. Fujii, I. Tokimitsu, and L. Saito. 2006. Chlorogenic acid attenuates hypertension and improves endothelial function in spontaneously hypertensive rats. J. Hypertens. 24:10651073.

Valko, M., M. Izakovic, M. Mazur, C.J. Rhodes, and J. Telser. 2004. Role of oxygen radicals in DNA damage and cancer incidence. Mol. Cell. Biochem. 266:37-56.

van Dam, R.M., N. Naidoo, and R. Landberg. 2013. Dietary flavonoids and the development of type 2 diabetes and cardiovascular diseases: Review of recent findings. Curr. Opin. Lipidol. 24:2533.

Velasco, P., M.E. Cartea, C. Gonzalez, M. Vilar, and A. Ordas. 2007. Factors affecting the glucosinolate content of kale (Brassica oleracea acephala group). J. Agr. Food Chem. 55:955-962.

Wang, S.Y., L. Bowman, and M. Ding. 2008. Methyl jasmonate enhances antioxidant activity and flavonoid content in blackberries (Rubus sp.) and promotes antiproliferation of human cancer cells. Food Chem. 107:12611269.

Zangerl, A.R. and F.A. Bazzaz. 1992. Theory and pattern in plant defense allocation, p. ix. In: Fritz, R.S. and E.L. Simms (eds.). Plant resistance to herbivores and pathogens: Ecology, evolution, and genetics. University of Chicago Press, Chicago, IL. 